\title{
Coronavirus Disease 2019 and Antibiotic Stewardship-Antibiotic Usage in Adult Patients: Is It Necessary? When Should It be Concerned?
}

\author{
Uğur Önal@, Halis Akalın®
}

Department of Infectious Diseases and Clinical Microbiology, Uludağ University School of Medicine, Bursa, Turkey

Antibiotic consumption rates were quite high in number, although the bacterial coinfection rates were low in coronavirus disease 2019 pneumonia. Generally, empirical antibiotic treatment is not recommended for uncomplicated coronavirus disease 2019 mild to moderate pneumonia cases. On the other hand, antibiotic treatment and de-escalation are recommended for intubated intensive care unit patients or critical patients with sepsis, septic shock, or acute respiratory distress syn- drome. The presentation of patients with severe coronavirus disease 2019 pneumonia can direct the clinicians to use antibiotics. We believe that wait and watch strategy can be preferred in such cases without sepsis, secondary bacterial infection findings, or procalcitonin $<0.5 \mathrm{ng} /$ $\mathrm{mL}$. We think that a new wave of resistance will occur inevitably if we cannot perform the antibiotic stewardship properly.
Antibiotic resistance rates and infections due to antibiotic-resistant pathogens were seen frequently with increasing numbers such that every year approximately 2.8 million antibiotic-resistant infections were recorded with 35,000 deaths as a consequence in the United States according to the Centers for Disease Control and Prevention 2019 report. ${ }^{1}$

Similar to this, more than 670,000 people were infected with antibiotic-resistant bacteria, with approximately 33,000 deaths in the countries of the European Union every year. ${ }^{2}$

With respect to infectious diseases, decreasing the resistance rates to minimal levels using appropriate empirical treatment and preventing collateral damage should be the main goals. ${ }^{3}$

Through many studies, it has been shown that antibiotic consumption leads to antibiotic resistance in bacteria. ${ }^{4}$

Despite all efforts, the inappropriate antibiotic consumption rate ranges between $30 \%$ and $50 \%{ }^{5}$ Antibiotic consumption rates and the rates of antibiotic resistant bacteria are increasing with coronavirus disease 2019 (COVID-19) pandemic. The aim of this paper is to review the antibiotic stewardship in patients with COVID-19.

\section{COVID-19 and clinical presentations}

Severe acute respiratory syndrome coronavirus 2 (SARS-CoV-2) is an enveloped RNA virus that belongs to the family of beta-coronaviruses and causes different clinical presentations such as asymptomatic or mild infection in nearly $80-90 \%$ of the patients and severe infection in $10 \%$ of the patients with the signs of dyspnea, hypoxia, or diffuse radiological involvement and critical infection, such as respiratory failure with intensive care unit (ICU) indications, pneumonia, shock, acute respiratory distress syndrome (ARDS), multiple organ failure, or death in 5\% of the patients with COVID-19. ${ }^{6}$ COVID-19 has three stages that have the following characteristic features: viral response in the early infection phase (stage 1), inflammatory response and pulmonary involvement (stage 2), and hyperinflammatory phase with extreme host inflammatory response (stage 3$)^{7}$

The National Institutes of Health (NIH) COVID-19 guideline summarizes the diseases into five different presentations: asymptomatic or presymptomatic disease; mild and moderate disease; severe disease with the findings of oxygen saturation $\left(\mathrm{SpO}_{2}\right)<94 \%$ in the room air at sea level, ratio of arterial oxygen partial pressure to fractional inspired oxygen $<300 \mathrm{~mm} \mathrm{Hg}$, respiratory rate $>30$ breaths per minute, or radiologically $>50 \%$ of lung involvement; and critical disease presenting with respiratory failure, septic shock, and/or multiple organ failure. ${ }^{8}$

The World Health Organization (WHO) also categorizes COVID-19 into mild disease; moderate disease/pneumonia; severe disease/pneumonia on the basis of some findings, including pneumonia symptoms such as fever, cough, dyspnea, tachypnea or respiratory rate $\geq 30$ breaths per minute, or severe respiratory distress or $\mathrm{SpO}_{2}<90 \%$; and critical disease presenting with ARDS, sepsis, or septic shock. ${ }^{9}$ 


\section{Influenza and bacterial coinfection}

Viral respiratory tract and bacterial coinfections are mostly observed in influenza, and a major part of our experience regarding these coinfections originated from this disease. In a systematic review and meta-analysis, Klein et al. ${ }^{10}$ investigated 27 studies on influenza and bacterial coinfections with a total of 3,215 patients, and they found that coinfection rate differed by $2-65 \%$ with high heterogeneity $\left(I^{2}=95 \%\right)$ of data.

\section{COVID-19: Bacterial coinfection and antibiotic usage}

From the beginning of SARS-CoV-2 pandemic, the most striking point is that the rates of antibiotic consumption are too high despite the fact that bacterial coinfection is rare (Table 1).

In addition to that, bacterial coinfection rates might be less owing to no or inadequate production of sputum in many of these patients and because cultures with urinary antigen tests could not be performed in every center. ${ }^{11,12}$

Another important point is that the discrimination of bacterial coinfections and secondary infections could not be reported in some of the studies.

Karami et al. ${ }^{13}$ retrospectively investigated a total of 925 patients with COVID-19, which was confirmed by polymerase chain reaction (PCR), from four different centers in the Netherlands between March and May 2020, and they found that only 1.2\% (12 of 925) of the patients with eight pneumonia cases had documented bacterial coinfection in the first week of hospitalization. In-hospital mortality was found to be $23.3 \%$ with $21.9 \%(n=166)$ of the patients needing ICU admission, and the diagnostic tests performed in the 925 cases were sputum culture $(n=105,11.3 \%)$, blood culture ( $\mathrm{n}=711,76.9 \%)$, urinary pneumococcal antigen test $(n=202,21.8 \%)$, and urinary legionella antigen test $(n=199$, $21.5 \%$ ). Among the patients with bacterial pneumonia, sputum cultures of seven patients and sputum culture of one patient with urinary pneumococcal antigen were positive, and blood cultures of four patients were positive. Sputum culture results showed Staphylococcus aureus in the culture of four patients, S. aureus plus Klebsiella oxytoca in the culture of one patient, Stenotrophomonas maltophilia in the culture of one patient, Haemophilus parainfluenzae in the culture of one patient, and H. influenza in the culture of one patient. In total, empirical antibiotic treatment was started in $60.1 \%$ of the patients in the first 24 hours, and these antibiotic treatments were recorded as cefuroxime $37.8 \%$, ceftriaxone $10.3 \%$, combination treatment $5.7 \%$, amoxicillin or benzylpenicillin $3.7 \%$, and others $3.1 \%{ }^{13}$

Hughes et al. ${ }^{14}$ studied a retrospective cohort from England containing a total of 836 patients with confirmed COVID-19 infection. They found bacterial isolates in 27 patients $(3.2 \%)$ within the first 5 days of hospitalization, whereas after the first five days of hospitalization, they found an increase of bacterial isolates to 51 patients $(6.1 \%)$.

Garcia-Vidal et al. ${ }^{15}$ published a study containing 925 patients with COVID-19 from Spain whose duration of hospitalization was at least 48 hours between February and April 2020, and they confirmed a total of 88 microbiological infections in 72 patients $(7.2 \%)$; the infections were caused by the following pathogens: bacteria (74), fungi (7), and virus (7). Community-acquired infection rate was found to be $3.1 \%$ (31 of 989 ) in this study, and a total of 43 patients $(4.7 \%)$ had a hospital-acquired infection with a mean duration of 10.6 (standard deviation $= \pm 6.6$ ) days. The total mortality rate was found to be $9.8 \%$ (97 of 989). At diagnosis, concomitant community-acquired pneumonia was recorded in $3.1 \%$ (31 of 898) of the patients, and the main pathogens were Streptococcus pneumoniae $(\mathrm{n}=12$ of 21; $57.1 \%$ ) and $S$. aureus ( $=6$ of $21 ; 28.6 \%) .{ }^{15}$

Vaughn et al. ${ }^{16}$ investigated a total of 1,705 patients with COVID-19 from 38 hospitals in the United States between March and June 2020 , and they reported that the mean empirical antibiotic initiation rate, which varied between different hospitals $(27-84 \%)$, was $56.6 \%$ (965 of 1,705), although the community-acquired infection rate was found to be $3.5 \%$ (59 of 1,705). In this study, empirical antibiotic treatment was given at high rates to the groups of elderly patients, patients with low body mass index, patients with severe disease such as sepsis, patients with lobar infiltration, and patients from private hospitals, and they found a correlation because increasing the rates of the results within one day led to a decrease in the usage of antibiotics. ${ }^{16}$

A total of 3,338 patients with COVID-19 from the 24 studies that were published between 2019 and April 2020 were investigated in a meta-analysis by Lanford et al. ${ }^{17}$ and they found that the bacterial infection rate was $6.9 \%$, the bacterial coinfection rate at the admission was $3.5 \%$, and the secondary bacterial infection rate was $14.3 \%$. They also showed that bacterial infections were more common in the ICUs $(8.1 \%)$ and that the majority of the patients with COVID-19 (71.9\%) received antibiotic treatment. ${ }^{17}$

TABLE 1. Incidence of bacterial community-acquired coinfections or bacterial coinfections detected within the first 5 days and the overall incidence of empirical antibiotic use

\begin{tabular}{|c|c|c|c|c|}
\hline Study (reference number) & $\begin{array}{l}\text { The overall incidence } \\
\text { of empirical antibiotic } \\
\text { use (\%) }\end{array}$ & $\begin{array}{l}\text { Incidence of bacterial community- } \\
\text { acquired infections or bacterial } \\
\text { coinfections detected within the } \\
\text { first } 5 \text { days }(\%)\end{array}$ & $\begin{array}{l}\text { Diagnostic methods } \\
\text { for bacterial infection }\end{array}$ & $\begin{array}{l}\text { Total number } \\
\text { of patients with } \\
\text { COVID-19 }\end{array}$ \\
\hline Karami et al. ${ }^{13}$ & 60.1 & 1.2 & Cultures and urinary antigen tests & 925 \\
\hline Hughes et al. ${ }^{14}$ & ND & 3.2 & Cultures & 836 \\
\hline Garcia-Vidal et al. ${ }^{15}$ & ND & 3.1 & Cultures & 925 \\
\hline Vaughn et al. ${ }^{16}$ & 56.6 & 3.5 & Cultures & 1,705 \\
\hline
\end{tabular}


A total of 3,834 patients from 30 studies were investigated in another meta-analysis, which was about coinfections in patients with COVID-19, and the overall bacterial coinfection rate was found to be $7 \%$, and the bacterial coinfection rate was found to be $14 \%$ in the ICUs. In addition to this, viral coinfection rate was found to be $3 \%$, and the most common causes were reported as respiratory syncytial virus and influenza A virus. ${ }^{18}$

Data on the prevalence of bacterial coinfections among patients admitted to the ICU within the first 48 hours of admission show that bacterial coinfection rate differs from $28 \%$ to $35 \% .{ }^{17}$ The most frequently isolated pathogens were reported to be $S$. aureus, $H$. influenzae, S. pneumoniae, and Enterobacteriaceae..$^{19,20}$

How can we decrease the inappropriate antibiotic consumption in these cases? The answer is antibiotic stewardship and prevention of the disease through vaccines. Inappropriate antibiotic consumption would decrease with the widespread use of vaccines for controlling the numbers of COVID-19 cases. In addition to this, the vaccines will also reduce inappropriate antibiotic consumption by preventing the severe disease. ${ }^{21,22}$

COVID-19 and decision of antibiotic treatment: When to start? According to the WHO recommendations, similar to patients with mild to moderate pneumonia, antibiotic treatment should not be

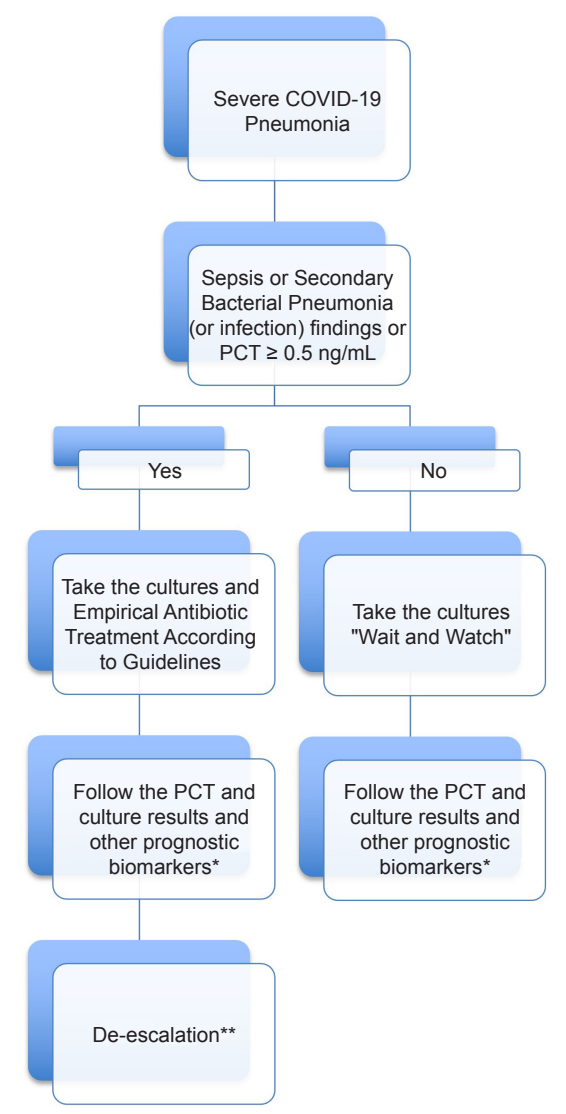

FIG. 1. Antibiotic stewardship in severe COVID-19 pneumonia. ${ }^{*}$ Cytokines, hsCRP, LDH, hsCRP/Lymphocyte level, Ferritin, D-dimer. ${ }^{27,32}$ ${ }^{* *}$ Duration of antibiotic therapy should be guided by a validated measure of clinical stability and should be continued until the patients achieves stability and for no less than a total five days. ${ }^{38}$ given to patients with uncomplicated COVID-19 unless there is a suspicion of bacterial infection, clinically. Close follow-up was recommended for patients with risk factors in terms of progression, and antibiotics such as amoxicillin/clavulanate can be considered, especially for elderly patients who stay in long-term care facilities for a long time. ${ }^{9}$

A study group from the Netherlands prepared an evidence-based guideline that also recommends limited use of antibiotics, especially for the mild-moderate group of patients with confirmed or highly probable COVID-19 infection, at the time of admission except for severe or immunocompromised patients or patients who have radiological/inflammatory signs compatible with bacterial coinfection in terms of antibiotic stewardship in patients with COVID-19. ${ }^{23}$

COVID-19 treatment guideline of the NIH emphasizes that there are not enough data for the initiation of wide-spectrum antibiotics unless there is another indication for severe or critical patients with COVID-19, and there are limited data for pulmonary coinfection or superinfection, such as hospital-acquired pneumonia or ventilator-associated pneumonia, in the terms of etiology or frequency. Some clinicians have doubts about bronchoscopy in these patients, and some experienced clinicians prefer to use wide-spectrum antibiotics routinely, whereas others do not; antibiotic treatment should be a part of the standard treatment if there is a shock in terms of antibiotic stewardship. ${ }^{24}$

From our point of view, the most controversial subject-whether antibiotic treatment should be given or not-is about patients with severe COVID-19 pneumonia. The severity of the disease in patients; high morbidity and mortality in severe COVID-19 pneumonia; diagnostic difficulty in distinguishing viral pneumonia from bacterial coinfections; the possibility of high acute-phase reactant levels, such as C-reactive protein (CRP) and procalcitonin (PCT) in both bacterial coinfections and severe COVID-19 pneumonia; and difficulty in sputum examination owing to nonproductive cough in a majority of the patients can direct the clinician to use the empirical antibiotics, which leads to unnecessary antibiotic consumption in a case owing to viral pneumonia. However, we believe that together with the clinical features, measuring PCT plus other biomarkers can be helpful for making the decision about antibiotic use for the patients with severe COVID-19 whose bacterial coinfection rates and initial PCT levels are usually low.

\section{COVID-19 and biomarkers}

Chen et al. ${ }^{25}$ revealed bacterial coinfection rate to be $1 \%$ in 99 patients with COVID-19. They found that elevated PCT level was in $6 \%$ and elevated CRP level in $86 \%$. Guan et al. ${ }^{26}$ studied a total of 1,099 patients with severe or nonsevere COVID-19 and found that the $60.7 \%$ of the patients had CRP level $\geq 10 \mathrm{mg} / \mathrm{L}(81.5 \%$ for patients with severe COVID-19 and $56.4 \%$ for those with nonsevere COVID-19), whereas $5.5 \%$ of the patients had PCT level $\geq 0.5 \mathrm{ng} /$ $\mathrm{mL}(13.7 \%$ for patients with severe COVID-19 and 3.7\% for those with nonsevere COVID-19). ${ }^{26}$

Statistically significant relationship (OR: 6.33, 95\% confidence interval: 4.24-9.45) between the biomarkers such as CRP, PCT, lactate dehydrogenase (LDH), and D-dimer together with signs 
of lymphopenia, thrombocytopenia, and severity of the disease was shown in a meta-analysis on the biomarkers in patients with COVID-19.27

PCT level $\geq 0.8 \mathrm{ng} / \mathrm{mL}$ can be a cut-off level for distinguishing mixed pneumonia from influenza pneumonia (sensitivity of $91 \%$ and specificity of $68 \%$; more accurate if lobar pneumonia is present), and a negative predictive value was shown to be $91.9 \%$ for bacterial coinfection (94\% if it is in a shock clinic) for PCT levels $<0.29 \mathrm{ng} / \mathrm{mL} .{ }^{28,29}$ Zeng et al.$^{30}$ showed that cytokines, LDH, high-sensitive CRP (hsCRP), and the ratio of hsCRP levels to lymphocyte levels increased from the baseline values during a follow-up in critical patients with COVID-19.

Findings of new onset or relapsing fever (with the consideration of steroid usage), new onset of sputum or changing of sputum characteristics, new onset of leukocytosis and/or neutrophilia (with the consideration of steroid usage; bad prognostic factor for COVID-19), new onset of radiological findings (lobar or segmental consolidation, with or without grand glass opacity), new onset or an increase of oxygen demand and acute respiratory failure, sepsis, and worsening of symptoms after recovery period can be supportive for the secondary bacterial pneumonia in patients with COVID-19. ${ }^{31}$

We believe that wait and watch strategy with collection of the sputum and blood cultures can be performed for the patients with COVID-19 with severe pneumonia if the PCT level is $<0.5 \mathrm{ng} / \mathrm{mL}$; if cytokines, hsCRP, LDH, and the ratio of hsCRP to lymphocyte levels are decreasing; or if there is no lobar pneumonia, sepsis/ hypotension, neutrophilic leukocytosis, and supportive findings of secondary bacterial pneumonia. Antibiotic treatment can be considered if the PCT levels are increasing (can be a bad prognostic factor and should be considered with other biomarkers as well) ${ }^{32}$ or if the supportive findings of secondary bacterial pneumonia or sepsis (until the exclusion of infection) are present (Figure 1).

Although there is insufficient evidence regarding the role of PCT (with undetermined cut-off level) in deciding whether to initiate antibiotic treatment in patients with COVID-19, still, it is thought to be helpful. But increasing of low PCT levels after the first 7-10 days secondary to COVID-19 without a bacterial infection should also be considered..$^{33}$

Empirical antibiotic treatment within the first hour is recommended for patients with respiratory failure and for patients on mechanical ventilatory support, similar to patients with septic shock. ${ }^{34}$

According to another study, which was about the biomarkers for ICU patients with COVID-19, a negative predictive value was found to be $81 \%$ if PCT level was less than $0.25 \mu \mathrm{g} / \mathrm{L}$, and a positive predictive value was found to be $93 \%$ if PCT level was more than $1 \mu \mathrm{g} / \mathrm{L}$ for secondary bacterial infections, and PCT level was recommended rather than $\mathrm{CRP}$ level at the beginning of the disease in the terms of antibiotic initiation. ${ }^{35}$ International PCT guideline also recommends that PCT cut-off value should be $0.5 \mu \mathrm{g} / \mathrm{L}$ for ICU patients and that empirical antibiotic treatment should be initiated through clinical evaluation for the patients with uncertain clinical findings of bacterial infection if PCT level was more than or equal to $0.5 \mathrm{ug} / \mathrm{L} .^{36}$
De Waele et al. ${ }^{37}$ showed an algorithm in terms of antibiotic stewardship for ICU patients with COVID-19 that 5-7 days of antibiotic treatment can be started according to guidelines with de-escalation strategy on the basis of culture results if the patients have a septic shock; if there are radiological findings of bacterial pneumonia, such as local infiltrations in thorax tomography; or if there are findings of pneumonia in microbiological samples or rapid diagnostic tests together with consequent PCT levels. ${ }^{37}$

\section{Antibiotic treatment: Guideline recommendations}

Infectious Diseases Society of America community-acquired pneumonia guideline recommends using a standard antibiotic regimen of $\beta$-lactam plus a macrolide or fluoroquinolone for patients with severe pneumonia and readjusting the treatment on the basis of the presence of risk factors and if previous culture results for methicillin-resistant $S$. aureus and Pseudomonas aeruginosa are positive. ${ }^{38}$

National Institutes for Health and Care Excellence recommends doxycycline (200 mg on the first day and then $100 \mathrm{mg} /$ day), amoxicillin-clavulanate plus clarithromycin, or levofloxacin as the last option as oral antibiotic treatment and recommends amoxicillin-clavulanate plus clarithromycin, cefuroxime plus clarithromycin, or levofloxacin as the last option as intravenous antibiotic treatment. ${ }^{39}$

In the literature, coinfection rates of Mycoplasma pneumoniae were reported to be $0-4.6 \%$, Chlamydia pneumoniae rates were reported to be $0-1.3 \%$, and Legionella pneumophila rates were reported to be $0.32 \% \cdot{ }^{40-43}$ On the other hand, Mycoplasma and Chlamydia were not spotted according to a PCR-based study. ${ }^{44}$ Thus, the topic of empirical antibiotic treatment for atypical pathogens is open for discussion on the basis of these findings.

The guideline recommendations on antibiotic stewardship consist of continuous evaluation and feedback, step-down treatment, preparation of guidelines, restriction and approval of antibiotics, de-escalation, optimal dosage, and education..$^{45}$ In addition to 2016 guideline recommendations, previous authorization and/or re-evaluation of the prescriptions with feedback, pharmacokinetic monitoring for aminoglycosides, stepdown, and reduction of the duration of antibiotic treatments are also recommended with high quality of evidence. ${ }^{46}$

PCT guided the reduction of the duration of antibiotic treatment De Jong et al. ${ }^{47}$ conducted a study containing critical patients in terms of PCT efficacy and reliability for the cessation and reduction of the duration of antibiotics in a randomized controlled clinical study with a cut-off level of $0.5 \mathrm{ng} / \mathrm{mL}$ or decreasing at least $80 \%$ of the baseline level. Standard treatment group (STG) and PCT-based treatment group (PBG) were compared in terms of antibiotic treatment duration: 5 days (PBG) compared with 7 days (STG) $(P<0.0001)$; they found the 28th-day mortality rates to be $16.9 \%$ for PBG and $25 \%$ for STG $(P=0.0122)$ and 1 -year mortality rates to be $34.8 \%$ for PBG and $40.9 \%$ for STG $(P=0.0158) .{ }^{47}$ Wirz et al. ${ }^{48}$ also performed a meta-analysis on ICU patients with sepsis and studied a total of 4,482 patients from 11 randomized studies, and they found that the mortality rates and antibiotic durations were significantly lower in the PCT-guided treatment group than in the standard follow-up group $(21.1 \%$ vs. $23.7 \% ; P=0.03$ and 9.3 days vs 10.4 days; $P<0.001)$. 
In conclusion, patients with uncomplicated COVID-19 and similar to those patients with mild-moderate pneumonia do not need antibiotic treatment, and these groups of patients should be monitored closely. On the other hand, antibiotic treatment can be individualized in patients with severe pneumonia, and PCT and other clinical plus laboratory findings can be helpful. Empirical treatment should be started in patients on mechanical ventilatory support or in those with sepsis or septic shock after the collection of cultures. Hospital flora and duration of stay in the hospital or ICU should be considered in terms of antibiotic selection. Steroid usage should also be considered as a risk factor for invasive fungal infections. Reducing the antibiotic durations through a de-escalation strategy should be aimed.

We have to remember that the resistance problem will continue to increase if we cannot perform the antibiotic stewardship properly in this pandemic period.

Author contributions: Concept - H.A.; Design - H.A.; Literature Review - U.Ö., H.A.; Writing - U.Ö., H.A.; Critical Review - H.A.

Conflict of Interest: The authors have no conflicts of interest to declare.

Funding: The authors declared that this study has received no financial support.

\section{REFERENCES}

1. CDC. Antibiotic Resistance Threats in the United States, 2019. Atlanta, GA: U.S. Department of Health and Human Services, CDC; 2019. doi: http://dx.doi. org/10.15620/cdc:82532

2. Cassini A, Högberg LD, Plachouras D, et al. Attributable deaths and disability-adjusted life-years caused by infections with antibiotic-resistant bacteria in the EU and the European Economic Area in 2015: a population-level modelling analysis. Lancet Infect Dis. 2019;19(1):56-66. [Crossref]

3. Paterson DL. "Collateral damage" from cephalosporin or quinolone antibiotic therapy. Clin Infect Dis. 2004;38(suppl 4):S341-345. [Crossref]

4. Bell BG, Schellevis F, Stobberingh E, Goossens H, Pringle M. A systematic review and meta-analysis of the effects of antibiotic consumption on antibiotic resistance. BMC Infect Dis. 2014;14:13. [Crossref]

5. Rowe TA, Linder JA. Novel approaches to decrease inappropriate ambulatory antibiotic use. Expert Rev Anti Infect Ther. 2019;17(7):511-521. [Crossref]

6. Pascarella G, Strumia A, Piliego C, et al. COVID-19 diagnosis and management: a comprehensive review. J Intern Med. 2020;288(2):192-206. [Crossref]

7. Siddiqi HK, Mehra MR. COVID-19 illness in native and immunosuppressed states: A clinical-therapeutic staging proposal. J Heart Lung Transplant. 2020;39(5):405407. [Crossref]

8. National Institutes of Health (NIH). COVID-19 Treatment Guidelines. https://www. covid19treatmentguidelines.nih.gov/ (accessed on Nov 30, 2020).

9. WHO Interim Guidance 27 May 2020. https://www.who.int/publications/i/item/clinical-management-of-covid-19 (accessed on Nov 30, 2020).

10. Klein EY, Monteforte B, Gupta A, et al. The frequency of influenza and bacterial coinfection: a systematic review and meta-analysis. Influenza Other Respir Viruses. 2016;10(5):394-403. [Crossref]

11. Huang C, Wang Y, Li X, et al. Clinical features of patients infected with 2019 novel coronavirus in Wuhan, China. Lancet. 2020;395(10223):497-506. [Crossref]

12. Saldias Peñafiel F, Gassmann Poniachik J, Canelo López A, Díaz Patiño O. Características clínicas de la neumonía adquirida en la comunidad del adulto inmunocompetente hospitalizado según el agente causal [Features of community-acquired pneumonia in immunocompetent hospitalized adults according to the causal agent]. Rev Med Chil. 2018;146(12):1371-1383. [Crossref]

13. Karami Z, Knoop BT, Dofferhoff ASM, et al. Few bacterial co-infections but frequent empiric antibiotic use in the early phase of hospitalized patients with COVID-19: results from a multicentre retrospective cohort study in The Netherlands. Infect Dis (Lond). 2021;53(2):102-110. [Crossref]

14. Hughes S, Troise O, Donaldson H, Mughal N, Moore LSP. Bacterial and fungal coinfection among hospitalized patients with COVID-19: a retrospective cohort study in a UK secondary-care setting. Clin Microbiol Infect. 2020;26(10):1395-1399. [Crossref]

15. Garcia-Vidal C, Sanjuan G, Moreno-García E, et al. Incidence of co-infections and superinfections in hospitalized patients with COVID-19: a retrospective cohor study. Clin Microbiol Infect. 2021;27(1):83-88. [Crossref]

16. Vaughn VM, Gandhi T, Petty LA, et al. Empiric antibacterial therapy and community-onset bacterial co-infection in patients hospitalized with COVID-19: a multi-hospital cohort study. Clin Infect Dis. 2020;21:ciaa1239. [Crossref]

17. Langford BJ, So M, Raybardhan S, et al. Bacterial co-infection and secondary in fection in patients with COVID-19: a living rapid review and meta-analysis. Clin Microbiol Infect. 2020;26(12):1622-1629. [Crossref]

18. Lansbury L, Lim B, Baskaran V, Lim WS. Co-infections in people with COVID-19: a systematic review and meta-analysis. $J$ Infect. 2020; 81(2):266-275. [Crossref]

19. Contou D, Claudinon A, Pajot O, et al. Bacterial and viral co-infections in patients with severe SARS-CoV-2 pneumonia admitted to a French ICU. Ann Intensive Care. 2020;10(1):119. [Crossref]

20. Kolenda C, Ranc AG, Boisset S, et al. Assessment of Respiratory Bacterial Coinfections Among Severe Acute Respiratory Syndrome Coronavirus 2-Positive Patients Hospitalized in Intensive Care Units Using Conventional Culture and BioFire, FilmArray Pneumonia Panel Plus Assay. Open Forum Infect Dis. 2020; 7(11):ofaa484. doi: 10.1093/ofid/ofaa484. [Crossref]

21. Polack FP, Thomas SJ, Kitchin N, et al. Safety and Efficacy of the BNT162b2 mRNA Covid-19 Vaccine. $N$ Engl J Med. 2020;383(27): 2603-2615. [Crossref]

22. Baden LR, El Sahly HM, Essink B, et al. Efficacy and Safety of the mRNA-1273 SARS-CoV-2 Vaccine. N Engl J Med. 2020;384(5):403-416. [Crossref]

23. SieswerdaE, deBoerMGJ, Bonten MMJ, etal. Recommendations for antibacterial therapy in adults with COVID-19-an evidence based guideline. Clin Microbiol Infect. 2020; 27(1):61-66. [Crossref]

24. COVID-19 Treatment Guidelines Panel. Coronavirus Disease 2019 (COVID-19) Treatment Guidelines. National Institutes of Health. https://www.covid19treatmentguidelines.nih.gov/. (accessed Nov 25, 2020).

25. Chen N, Zhou M, Dong X, et al. Epidemiological and clinical characteristics of 99 cases of 2019 novel coronavirus pneumonia in Wuhan, China: a descriptive study. Lancet. 2020;395(10223):507-513. [Crossref]

26. Guan WJ, Ni ZY, Hu Y, et al. Clinical Characteristics of Coronavirus Disease 2019 in China. N Engl J Med. 2020;382(18):1708-1720. [Crossref]

27. Malik P, Patel U, Mehta D, et al. Biomarkers and outcomes of COVID-19 hospitalisations: systematic review and meta-analysis. BMJ Evid Based Med. 2020:bmjebm-2020-111536. doi: 10.1136/bmjebm-2020-111536. [Crossref]

28. Antonelli M, Bonten $\mathrm{M}$, Chastre J, et al. Year in review in Intensive Care Medicine 2011. II. Cardiovascular, infections, pneumonia and sepsis, critical care organization and outcome, education, ultrasonography, metabolism and coagulation. Intensive Care Med. 2012;38(3):345-358. [Crossref]

29. Rodríguez AH, Avilés-Jurado FX, Díaz E, et al. Procalcitonin (PCT) levels for ruling-out bacterial coinfection in ICU patients with influenza: A CHAID decision-tree analysis. J Infect. 2016;72(2):143-151. [Crossref]

30. Zhilin Z, Haijing Y, Huilong C, et al. Longitudinal changes of inflammatory parameters and their correlation with disease severity and outcomes in patients with COVID-19 from Wuhan, China. Crit Care. 2020;24(1):525. [Crossref]

31. Wu CP, Latifi M, Mireles-Cabodevila E. Management of patients with COVID-19 in the MICU. Cleveland Cleve Clin J Med. 2020;87(9):526-531. [Crossref]

32. Liu ZM, Li JP, Wang SP, et al. Association of procalcitonin levels with the progression and prognosis of hospitalized patients with COVID-19. Int J Med Sci. 2020;17(16):2468-2476. [Crossref]

33. Massachusetts General Hospital (MGH) COVID-19 Treatment Guidance. Version 7.0 11/13/2020. https://www.massgeneral.org/assets/MGH/pdf/news/coronavirus/ mass-general-COVID-19-treatment-guidance.pdf (accessed Nov 30, 2020)

34. Alhazzani W, Møller MH, Arabi YM, et al. Surviving Sepsis Campaign: guidelines on the management of critically ill adults with Coronavirus Disease 2019 (COVID-19). Intensive Care Med. 2020;46(5):854-887. [Crossref]

35. van Berkel M, Kox M, Frenzel T, Pickkers P, Schouten J, RCI-COVID-19 study group. Biomarkers for antimicrobial stewardship: a reappraisal in COVID-19 times? Crit Care. 2020;24:600. [Crossref] 
36. Schuetz P, Beishuizen A, Broyles M, et al. Procalcitonin (PCT)-guided antibiotic stewardship: An international experts consensus on optimized clinical use. Clin Chem Lab Med. 2019;57(9):1308-1318. [Crossref]

37. De Waele JJ, Derde L, Bassetti M. Antimicrobial stewardship in ICUs during the COVID-19 pandemic: back to the 90s? Intensive Care Med. 2020:47(1):104-106. [Crossref]

38. Metlay JP, Waterer GW, Long AC, et al. Diagnosis and Treatment of Adults with Community-acquired Pneumonia. An Official Clinical Practice Guideline of the American Thoracic Society and Infectious Diseases Society of America. Am J Respir Crit Care Med. 2019;200(7):e45-e67. [Crossref]

39. NICE. Covid-19 rapid guideline: antibiotics for pneumonia in adults in hospital https://www.nice.org.uk/guidance/ng173/resources/covid19-rapid-guideline-antibiotics-for-pneumonia-in-adults-in-hospital-pdf-66141959536069 (accessed on Nov 30, 2020)

40. Zha L, Shen J, Tefsen B, Wang Y, Lu W, Xu Q. Clinical features and outcome of adult COVID-19 patients co-infected with Mycoplasma pneumoniae. J Infect. 2020;81(3):e12-e15. [Crossref]

41. Gayam V, Konala VM, Naramala S, et al. Presenting characteristics, comorbidities, and outcomes of patients coinfected with COVID-19 and Mycoplasma pneumoniae in the USA. J Med Virol. 2020; 92(10):2181-2187. [Crossref]

42. Oliva A, Siccardi G, Migliarini A, et al. Co-infection of SARS-CoV-2 with Chlamydia or Mycoplasma pneumoniae: a case series and review of the literature. Infection. 2020;48(6):871-877. [Crossref]
43. Davis B, Rothrock AN, Swetland S, Andris H, Davis P, Rothrock SG. Viral and atypical respiratory co-infections in COVID-19: a systematic review and meta-analysis. J Am Coll Emerg Physicians Open. 2020;1(4):533-548. [Crossref]

44. Kim D, Quinn J, Pinsky B, Shah NH, Brown I. Rates of Co-infection Between SARS-CoV-2 and Other Respiratory Pathogens. JAMA. 2020;323(20):2085-2086. [Crossref]

45. Dellit TH, Owens RC, McGowan Jr JE, et al. Infectious Diseases Society of America and the Society for Healthcare Epidemiology of America guidelines for developing an institutional program to enhance antimicrobial stewardship. Clin Infect Dis. 2007;44(2):159-177. [Crossref]

46. Barlam TF, Cosgrove SE, Abbo LM, et al. Implementing an Antibiotic Stewardship Program: Guidelines by the Infectious Diseases Society of America and the Society for Healthcare Epidemiology of America. Clin Infect Dis. 2016;62(10):e51-77. [Crossref]

47. de Jong E, van Oers JA, Beishuizen A, et al. Efficacy and safety of procalcitonin guidance in reducing the duration of antibiotic treatment in critically ill patients: a randomised, controlled, open-label trial. Lancet Infect Dis. 2016;16(7):819-827. [Crossref]

48. Wirz Y, Meier MA, Bouadma L, et al. Effect of procalcitonin-guided antibiotic treatment on clinical outcomes in intensive care unit patients with infection and sepsis patients: a patient-level meta-analysis of randomized trials. Crit Care. 2018;22(1):191. [Crossref] 